\title{
Tracheostomy in Pediatric Intensive Care Unit-A Two Decades of Experience
}

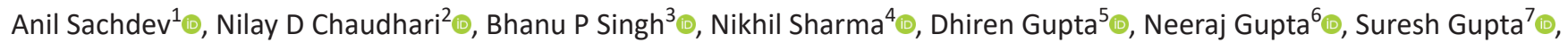
Parul Chugh ${ }^{8}$ (I)

\begin{abstract}
Aim and objective: To study the profile, indications, related complications, and predictors of decannulation and mortality in patients who underwent tracheostomy in the pediatric intensive care unit (PICU).

Materials and methods: Retrospective analysis of prospectively collected data of tracheostomies was done on patients admitted at PICU. Demographics, primary diagnosis, indication of tracheostomy, and durations of endotracheal intubation, mechanical ventilation, and tracheostomy cannulation were recorded. The indication was recorded in one of the four categories-upper airway obstruction (UAO), central neurological impairment (CNI), prolonged mechanical ventilation, and peripheral neuromuscular disorders).

Results: Two hundred ninety cases were analyzed. UAO (42\%) and CNI (48.2\%) were main indications in the halves of the study period, respectively. Decannulation was successful in $188(64.8 \%)$ patients. Seventy-seven percentage UAO patients were decannulated successfully [OR (odds ratio); $95 \% \mathrm{Cl}$ (confidence interval), $2.647 ; 1.182-5.924, p=0.018]$. Age $<1$ year $(0.378 ; 0.187-0.764 ; p=0.007)$, nontraumatic, noninfectious central neurological diseases $(0.398 ; 0.186-0.855 ; p=0.018)$, and malignancy $(0.078 ; 0.021-0.298 ; p<0.001)$, durations of posttracheostomy ventilation $(0.937 ; 0.893-0.983 ; p=0.008)$, and stay in the PICU $(0.989 ; 0.979-0.999 ; p=0.029)$ were predictors of unsuccessful decannulation. There were 91 (31.4\%) deaths. Age $<1$ year $(2.39(1.13-5.05 ; p=0.02)$, malignancy $(17.55 ; 4.10-75.11 ; p<0.001)$, durations of posttracheostomy ventilation $(1.06 ; 1.006-1.10 ; p=0.028)$, and hospital stay $(1.007 ; 1.0-1.013 ; p=0.043)$ were independent predictors of mortality. Indication of UAO favored survivor $(0.24 ; 0.09-0.57 ; p<0.001)$.

Conclusion: The indications for tracheostomy in children had changed over the years. Infancy, primary diagnosis, length of posttracheostomy ventilation, and stay in the PICU and hospital were independent predictors of decannulation and mortality.

What This Adds

Similar to developed countries, the age at the time of tracheostomy and indication are changing. Inability to decannulate and mortality were associated with the age of a child at the time of tracheostomy, indication, medical diagnosis, and duration of postprocedure mechanical ventilation and stay in the hospital.

Keywords: Artificial airway, Decannulation, Outcome, Pediatric critical care, Tracheostomy.

Indian Journal of Critical Care Medicine (2021): 10.5005/jp-journals-10071-23893.
\end{abstract}

\section{INTRODUCTION}

Tracheostomy is a lifesaving procedure with potential complications. The indications for tracheostomy have shown a changing trend over the decades. In the 1970s, the inflammatory causes resulting in upper airway obstruction (UAO) were the most common indication for this procedure. Now in the pediatric and neonatal population, tracheostomy is required to relieve an obstructed or unstable airway due to congenital or noninfectious acquired causes, to assist long-term ventilation, or for a tracheobronchial toilet. ${ }^{1,2}$ The role of tracheostomy and related outcomes in children has steadily evolved with improving critical care services. Although earlier reviews of the medical literature show pediatric tracheostomy to have two to three times more morbidity and mortality than adults, recent studies suggest that the incumbent risks in children are not as high as once perceived. ${ }^{3-5}$ The published data on pediatric tracheostomy is on specific groups of patients, such as burn or trauma victims or neonates. ${ }^{6,7}$ There are few epidemiological surveys and research studies on the impact of tracheostomy on morbidity and mortality in children admitted in the pediatric intensive care unit (PICU). ${ }^{8-14}$ Our objectives were to study the profile, indications, related complications, and predictors of decannulation and mortality in patients who underwent tracheostomy in the PICU setting of a developing country.
1-5,7 Department of Pediatrics, Sir Ganga Ram Hospital, New Delhi, India ${ }^{6}$ Department of Pediatric Intensive Care, Sir Ganga Ram Hospital, New Delhi, India

${ }^{8}$ Department of Research, Sir Ganga Ram Hospital, New Delhi, India

Corresponding Author: Anil Sachdev, Department of Pediatric, Sir Ganga Ram Hospital, New Delhi, India, Phone: +91 9810098360, e-mail: anilcriticare@gmail.com

How to cite this article: Sachdev A, Chaudhari ND, Singh BP, Sharma N, Gupta D, Gupta N, et al. Tracheostomy in Pediatric Intensive Care Unit-A Two Decades of Experience. Indian J Crit Care Med 2021;25(7):803-811.

Source of support: Nil

Conflict of interest: None

\section{Methods and Materials}

\section{Study Setting, Design, and Data Collection}

The study was conducted at a multispecialty teaching hospital with state-of-the-art pediatric critical care services. Clearance from the institutional research and ethics committee was obtained. This was a retrospective

(0) Jaypee Brothers Medical Publishers. 2021 Open Access This article is distributed under the terms of the Creative Commons Attribution 4.0 International License (https://creativecommons.org/licenses/by-nc/4.0/), which permits unrestricted use, distribution, and non-commercial reproduction in any medium, provided you give appropriate credit to the original author(s) and the source, provide a link to the Creative Commons license, and indicate if changes were made. The Creative Commons Public Domain Dedication waiver (http://creativecommons.org/publicdomain/zero/1.0/) applies to the data made available in this article, unless otherwise stated. 
analysis of prospectively collected data of tracheostomies done on patients admitted to the PICU from January 2000 to December 2018. Data were recorded in preformed data sheet in the initial years, and later with the availability of internet and computers, it was captured in excel data sheet. Missing parameters, if any, were collected from medical charts. Demographics, primary diagnosis, indication of tracheostomy, and durations of endotracheal intubation, pre- and postcannulation mechanical ventilation, and tracheostomy cannulation were recorded. Length of stay in PICU and hospital were also recorded. The clinical diagnosis was classified according to the primary organ/ system involved. Indication was defined as the fundamental reason (separate from primary clinical diagnosis) for tracheostomy placement. Indication was recorded in one of the four categories. Patients with congenital or acquired airway diseases leading to obstructive airways were categorized under UAO. This included isolated or in combination congenital laryngeal, tracheal, and bronchial airway anomalies, craniofacial deformities, facial and airway trauma, and acquired upper airway lesions like subglottic stenosis and corrosive and inhalational injuries. Patients with central neurological impairment (CNI) while on mechanical ventilation required tracheostomy because of their inability to protect the airway, recurrent aspiration and apnea, and for airway toilet. Similarly, patients with peripheral neuromuscular diseases (NMD), peripheral neuropathy, or muscular diseases required tracheostomy for airway toilet, home ventilation, and airway protection. We have assigned the prolonged mechanical ventilation (PMV) category to patients who were on invasive ventilation for sepsis, inflammatory diseases, and cardiopulmonary diseases for $\geq 14$ days.

The decision for tracheostomy was taken by the intensivist, otorhinolaryngologist, and primary pediatrician collectively. Semiemergency tracheostomy was defined as a procedure done as a lifesaving measure after the initiation of advanced airway management. All other tracheostomies were performed as planned elective procedures. All tracheostomies were performed as an open procedure in the operation room under general anesthesia by an otorhinolaryngologist. Postprocedure patients were monitored in the PICU for a week or till the first tube change. The first tube change by the surgeon was done in the PICU on day 7 after ensuring maturity of the tracheostomy track. Complications occurring immediately (intraoperative and within 24 hours), early ( $<7$ days), and late ( $\geq 7$ days) were recorded.

Patient's age $<1$ month, patients with tracheostomy done in the neonatal care unit of our hospital and in other hospitals and now admitted in our unit for critical care for a related or unrelated illness, and patients with incomplete data were excluded from the study.

\section{Home Care, Parent's Education, and Follow-up}

All parents were trained about the routine care of tracheostomy tube and stoma as well as tube change and basic cardiopulmonary resuscitation by the attending intensivist. They were educated about the features of a tube block or displacement and were provided with a written emergency action plan with facilities of immediate help in their vicinity for any life-threatening situation.
All patients were sent home with a spare tracheostomy tube, Ambu bag with mask, foot-operated suction machine, and proper size suction catheters. They were advised to change the tube every 10 to 14 days by an otorhinolaryngologist or by themselves if they were confident. The procedure of tube change by parents was witnessed by the educator before discharge.

After discharge, all patients were instructed for follow-up visits at 2-3 month intervals in the outpatient department by a pediatric pulmonologist and otorhinolaryngologist. Tracheostomy care was reemphasized. In case of a missed visit, parents were contacted telephonically or via postal mail to know the well-being of children before or after decannulation. In case of demises, possible cause, place, and date and month of death were noted. In case of no communication from parents, the last follow-up visit was noted to calculate the duration of tracheostomy in situ. The last enrolled patient was followed up for 1 year.

\section{Decannulation}

Decision for decannulation was taken in consultation with the otorhinolaryngologist. It was planned when the original indication for tracheostomy had resolved and the child was maintaining oxygen saturation $>92 \%$ on room air with acceptable work of breathing, had good cough reflex, and was able to handle respiratory secretions and with no evidence of infections in the chest or otherwise. A flexible bronchoscopy was performed prior to decannulation to check the structural and functional suitability of airways. ${ }^{15}$ Decannulation was done in the PICU by occluding the tracheostomy tube with an impermeable adhesive tape for 6 hours. Patients were monitored closely for cardiopulmonary instability. After decannulation, patients were monitored for 24 hours in the PICU and for another 24 hours in the ward.

\section{Statistical Analysis}

Patient characteristics were compared and described by appropriate statistics. Data were expressed as means (SD), medians (interquartile range [IQR]), and proportions as appropriate. MannWhitney $U$-tests were used to compare continuous variables, and chi-square test was used for categorical variables. Comparisons among various indications were performed using the KruskalWallis test for continuous variables. To identify potential factors associated with decannulation, univariate analyses were performed. A multivariate logistic regression model was used to identify independent risk factors for decannulation. A stepwise approach was used to enter the terms into the model, with a limit of $p<0.05$. Time-to-event variables were visualized using Kaplan-Meier curves for decannulation and survival. For all tests, a $p$ value $<0.05$ was considered statistically significant. A statistical analysis was conducted using SPSS version 17.0 (SPSS, Inc., Chicago, Illinois).

\section{Results}

Out of 306 tracheostomies performed in the PICU from 2000 to December 2018, 290 cases were analyzed (Flowchart 1). From 2010 to 2018 , there were 7,089 admissions in our PICU and, out of which, $2,462(34.7 \%)$ cases received invasive mechanical ventilation. One hundred sixty-four (6.7\%) cases underwent tracheostomy for various indications. Out of 290 tracheostomized patients, there were 210 males and the median (IQR) age was 36 (5-96) months. Moreover, 30/36 (83.3\%) children with airway-related diseases and 19/22 (86.4\%) with cardiopulmonary diseases were $<1$ year 


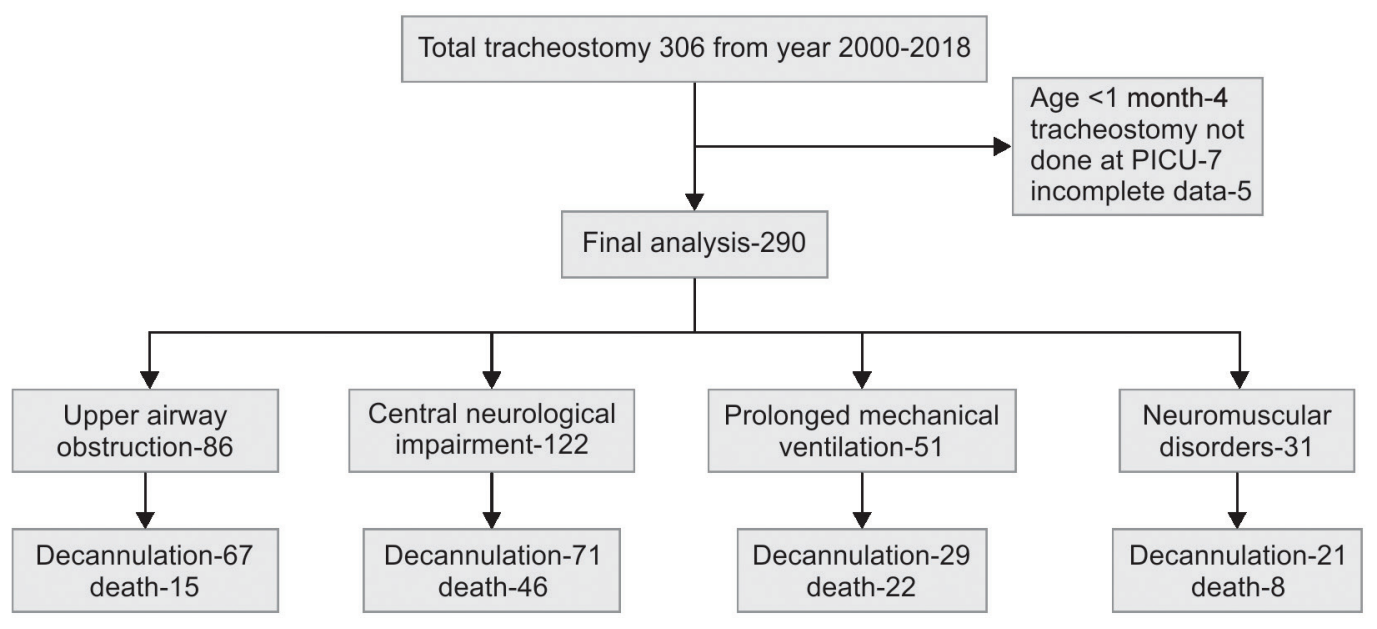

Flowchart 1: Study diagram

Table 1: Characteristic differences between year 2000-2009 and $2010-2018$

\begin{tabular}{lccc}
\hline Parameters & $\begin{array}{l}2000-2009 \\
(n=126)\end{array}$ & $\begin{array}{l}2010-2018 \\
(n=164)\end{array}$ & $p$ value \\
\hline Age (months) & $18(2,84)^{\mathrm{a}}$ & $60(10.7,120)$ & 0.0001 \\
Male & $98(77.8)$ & $112(68.3)$ & 0.07 \\
Indication & & & \\
UAO & $53(42.1)^{\mathrm{b}}$ & $33(20.1)$ & $<0.0001$ \\
CNI & $43(34.1)$ & $79(48.2)$ & 0.01 \\
PMV & $19(15.1)$ & $32(19.5)$ & 0.33 \\
NMD & $11(8.7)$ & $20(12.2)$ & 0.3 \\
Pretracheostomy ETI & $13(4,21)$ & $11(7,16)$ & 0.59 \\
Complications & & & \\
Immediate & $18(14.2)$ & $26(15.8)$ & 0.96 \\
Early & $14(11.1)$ & $24(14.6)$ & 0.91 \\
Late & $45(35.7)$ & $38(23.1)$ & 0.01 \\
FFB & & & \\
Pretracheostomy & $86(82)$ & $63(38.4)$ & $<0.0001$ \\
Posttracheostomy & $114(90.4)$ & $102(62.2)$ & $<0.0001$ \\
Duration of & $155(62,389)$ & $119.5(54,229.2)$ & 0.007 \\
tracheostomy (days) & & & \\
PICU stay (days) & $26.5(13,47.7)$ & $25(16,41.2)$ & 0.63 \\
Hospital stay (days) & $39(24,68)$ & $35(22.7,53)$ & 0.2 \\
Survivor & $89(70.6)$ & $110(67)$ & 0.42 \\
\hline
\end{tabular}

${ }^{\mathrm{a}}$ Median with interquartile range; ${ }^{\mathrm{b}}$ Number with percentage; UAO, upper airway obstruction; CNI, central neurological impairment; PMV, prolonged mechanical ventilation; NMD, neuromuscular disorder; ETI, endotracheal intubation; FFB, flexible fiberoptic bronchoscopy

of age, while $62.5 \%$ of patients with neoplastic diseases were over $>5$ years of age. Two hundred seventy-four children required pretracheostomy endotracheal intubation and ventilation and the median (IQR) duration of endotracheal intubation prior to tracheostomy was 12 (5-20) days. Table 1 compares patients' characteristics and outcomes from the year 2000 to 2009 and 2010 to 2018.

There were 31 semiemergency tracheostomies. There were 10 cases of subglottic stenosis ( 6 acquired and 4 congenital), 5 with severe mucositis (Stevens-Johnson syndrome and corrosive ingestion), 4 with severe laryngotracheomalacia, 4 with lifethreatening oral or pharyngeal infections, 3 with facial or airway injury, 2 with congenital laryngeal web, and one each of congenital bilateral vocal cord palsy, airway hemangioma, and severe midfacial deformity. Ten cases were not endotracheally intubated while the rest were intubated for a short time $(6.5 \pm 3.2$ hours) before tracheostomy tube placement.

The most common indication for tracheostomy was CNI followed by UAO (Table 2). The inability to protect the airway and failed extubation were the main reasons for tracheostomy in patients with CNI.

The majority of children had some form of infection or inflammatory disease (Table 3). Central nervous system infections of viral, bacterial, tubercular, and fungal etiology constituted $13.4 \%$ of the total cohort.

Tube malposition and bleeding at the operative site were the common immediate complications. Tube malposition was most frequent in patients $<1$ year of age in the first week of tracheostomy $(15 / 20)$. Similarly, tube block by a clot or mucus plug was also frequent in infants (11/15). Bleeding was minor and did not require any medical or surgical interventions (Table 4). Lung atelectasis and stomal and tracheal granulation formation were the common complications in the first week and later, respectively. Forty-one infection-related complications occurred in our patients.

Decannulation was successful in 188 (64.8\%) patients. The minimum duration of tracheostomy was 2 days in a child who died due to tube dislodgement and massive subcutaneous emphysema. The maximum duration of tracheostomy was 9.5 years in an infant with accidental corrosive ingestion and was still alive and attending school till last follow-up. The median duration of tracheostomy was maximal in patients with UAO and $77 \%$ were decannulated successfully. The success of decannulation varied with diagnosis - airway-related diseases (75\%), infection/inflammatory disorders (71.3\%), trauma/injury (82.2\%), cardiopulmonary diseases (40.9\%), nontraumatic, noninfectious central neurological diseases (47.5\%), malignancy (18.8\%), craniofacial/genetic diseases (52.9\%), neuromuscular diseases (69.6\%), and miscellaneous (75\%). Two children-one of postliver transplantation and the other of diffuse necrotizing myelitis-died at home after successful decannulation. Age $<1$ year at the time of tracheostomy, diagnosis of nontraumatic noninfectious central nervous system diseases and malignancy, and prolonged duration of posttracheostomy mechanical ventilation 
Table 2: Patient characterization and outcome according to indication of tracheostomy

\begin{tabular}{|c|c|c|c|c|c|}
\hline Variables & $U A O(n=86)$ & $C N I(n=122)$ & $\operatorname{PMV}(n=51)$ & $\operatorname{NMD}(n=31)$ & $p$ value \\
\hline Age (months) & $5(1.5,24)^{a}$ & $74(31,126)$ & $10(3,60)$ & $96(48,144)$ & $<0.001$ \\
\hline Male & $68(78.2)^{b}$ & $88(72.7)$ & $37(67.3)$ & $17(63)$ & 0.33 \\
\hline Duration ETi (days) & $2(1-10)$ & $11(8.5-15)$ & $24(16-30)$ & $12(9-21)$ & $<0.001$ \\
\hline Elective trach & $56(65.1)$ & $121(99.2)$ & $51(100)$ & $31(100)$ & $<0.0001$ \\
\hline FFB (Pre) No & $22(25.3)$ & $86(71.7)$ & $17(30.9)$ & $15(55.6)$ & \\
\hline 1 & $55(63.2)$ & $32(26.7)$ & $26(47.3)$ & $10(37)$ & $<0.001$ \\
\hline$\geq 2$ & $10(11.5)$ & $2(1.7)$ & $12(21.8)$ & $2(7.4)$ & \\
\hline FFB (post) No & $13(14.9)$ & $38(31.7)$ & $15(27.3)$ & $7(25.9)$ & \\
\hline 1 & $35(40.2)$ & $64(53.3)$ & $27(49.1)$ & $15(55.6)$ & 0.001 \\
\hline$\geq 2$ & $39(44.8)$ & $18(14.8)$ & $13(23.7)$ & $5(18.5)$ & \\
\hline \multicolumn{6}{|l|}{ Complications } \\
\hline Immediate & $18(20.7)$ & $13(10.7)$ & $8(14.5)$ & $2(7.4)$ & 0.15 \\
\hline Early & $11(12.8)$ & $9(7.4)$ & $12(21.8)$ & $3(11.1)$ & 0.02 \\
\hline Late & $36(41.3)$ & $24(19.8)$ & $16(29)$ & $13(48)$ & 0.01 \\
\hline LOS PICU (days) & $12(8,25)$ & $25(18.5,34.5)$ & $50(41,70)$ & $38(23,77)$ & $<0.0001$ \\
\hline LOS hospital (days) & $9(12,39)$ & $34(26.5,49.5)$ & $68(45,83)$ & $43(31,80)$ & $<0.0001$ \\
\hline Days of trach & $272(83,510)$ & $111(55.5209)$ & $75(34,165)$ & $154(87,310)$ & $<0.001$ \\
\hline \multicolumn{6}{|l|}{ Outcome } \\
\hline Survivor & $71(82.5)$ & $76(62.2)$ & $29(56.8)$ & $23(74.2)$ & 0.002 \\
\hline Alive w/o tube & $66(76.7)$ & $71(58.2)$ & $29(56.8)$ & $20(64.5)$ & 0.034 \\
\hline Alive with tube & $5(5.8)$ & $5(4.1)$ & 0 & $3(9.6)$ & - \\
\hline Died with tube & $14(16.2)$ & $46(37.7)$ & $22(43.1)$ & $7(22.5)$ & 0.001 \\
\hline $\begin{array}{l}\text { Died after } \\
\text { decannulation }\end{array}$ & 1 & 0 & 0 & 1 & - \\
\hline
\end{tabular}

UAO, upper airway obstruction; CNI, central neurological impairment; PMV, prolonged mechanical ventilation; NMD, neuromuscular disorders; ETI, endotracheal tube intubation; trach, tracheostomy; FFB, flexible fiberoptic bronchoscopy; LOS, length of stay; PICU, pediatric intensive care unit

and PICU stay were unfavorable independent risk factors for successful decannulation. UAO as an indication for tracheostomy was independently associated with decannulation (Table 5). The overall probability of decannulation and for individual indications is shown in Figure 1.

There were 91 (31.4\%) deaths in our cohort and the majority were due to underlying diseases. The maximum number of deaths occurred in children with malignancies (75\%) followed by cardiopulmonary diseases (59.1\%) while only 5 of $36(13.9 \%)$ children with airway-related diseases died ( $p$ value $<0.0001)$. There were nine (3.1\%) deaths directly related to tracheostomy. Seven children died because of tube block and massive surgical emphysema. Four of these deaths occurred in the hospital within 48 hours of tracheostomy and one died after 6 days of procedure in the hospital. Two children died at home due to accidental extubation and tube block. Two cases developed pneumonia and died at their native place. Age $<1$ year, malignancy, duration of posttracheostomy ventilation, and total length of hospital stay were independent risk factors for mortality while the indication of UAO was favorable for survival (Table 6). The probability of survival of the whole cohort among different indications was analyzed (Fig. 2). Three patients were lost during follow-up and were censored as alive as they were seen on the last visit.

Thirteen patients were alive with the tracheostomy tube in situ till the last follow-up. Five cases each required tracheostomy for airway protection and severe unresolved upper and lower airway diseases, two children had atlantoaxial dislocation resulting in respiratory and diaphragm paralysis, and one child with myopathy with cardiopulmonary compromise.

\section{Discussion}

This study was done at a tertiary-level PICU from 2000 to 2018. Infection/inflammatory diseases were the most common diagnostic category and CNI was the most common indication for tracheostomy tube placement. Younger children required tracheostomy mainly for UAO in the first 10 years as compared to subsequent years. Tube dislodgement and subsequent surgical emphysema were life-threatening complications in the immediate postprocedure period. Although the duration of tracheostomy was the longest in patients with UAO, the proportion of successful decannulation was higher in this group. Diagnosis of neoplastic diseases was associated with poor survival. A higher proportion of patients with $\mathrm{CNI}$ and PMV as indications died with the tracheostomy tube in situ.

Indications of pediatric tracheostomy are changing over the years. These varied according to the origin of the study and the year of publication. UAO due to infections like epiglottitis had been reported as the most common indication in the early 1970s. ${ }^{1}$ Later on, congenital or acquired anatomical narrowing of upper airways became frequent indications. ${ }^{16-18}$ In thirdworld countries, infections are still reported as a common 
Table 3: Diagnostic categories of study cohort

\begin{tabular}{|c|c|c|}
\hline Airway-related diseases (36) & Infection/inflammatory diseases (88) & Trauma/injury (45) \\
\hline Airway malacia (13) & Acute pneumonia (15) & $\mathrm{TBI}(25)$ \\
\hline $\operatorname{TEF}(5)$ & Meningitis/encephalitis (25) & Polytrauma (8) \\
\hline Congenital SGS (4) & Septicemia (15) & Corrosive ingestion (5) \\
\hline Acquired SGS (2) & TBM (14) & Drowning (3) \\
\hline Congenital laryngeal web (3) & SJS (3) & Facial injury (2) \\
\hline FB aspiration (3) & Hepatitis A (3) & Cervical spine injury (1) \\
\hline Airway cleft (2) & Retropharyngeal abscess (2) & Burns (1) \\
\hline Congenital vocal cord palsy (1) & Ludwig's angina (2) & Neoplasm/malignancy (16) \\
\hline Vocal cord dysfunction (1) & Acute myelitis (2) & Solid organ tumor (9) \\
\hline Obstructive sleep apnea (1) & Collagen vascular disorder (3) & Leukemia/lymphoma (5) \\
\hline Cystic hygroma (1) & Tropical diseases (4) & $\mathrm{LCH}(2)$ \\
\hline Cardiopulmonary diseases (22) & Craniofacial/genetic anomalies (17) & NM disorders (23) \\
\hline Chronic lung diseases (11) & Genetic diseases (13) & GBS (17) \\
\hline Congenital heart disease (6) & Retrognathia (2) & SMA (3) \\
\hline Cystic fibrosis (2) & Micrognathia (1) & Myopathy (3) \\
\hline Myocarditis/cardiomyopathy (3) & Macroglossia (1) & \\
\hline Nontraumatic/noninfectious & & Miscellaneous (4) \\
\hline \multicolumn{3}{|l|}{ central neurological diseases (39) } \\
\hline Static encephalopathy (16) & & Diabetic ketoacidosis (2) \\
\hline Immune-mediated encephalopathy (5) & & Biliary atresia (1) \\
\hline Superrefractory seizures (5) & & Facial hemangioma (1) \\
\hline Arteriovenous malformation (5) & & Atlantoaxial dislocation (3) \\
\hline \multicolumn{3}{|l|}{ Neuroregressive disorders (2) } \\
\hline \multicolumn{3}{|l|}{ Intraventricular bleed (2) } \\
\hline Spinal dysraphism (1) & & \\
\hline
\end{tabular}

TEF, tracheoesophageal fistula; SGS, subglottic stenosis; FB, foreign body; TBM, tubercular meningitis; SJS, Stevens-Johnson syndrome; TBI, traumatic brain injury; LCH, Langerhans cell histiocytosis; GBS, Guillain-Barre syndrome; SMA, spinomuscular atrophy

Table 4: Tracheostomy complications

\begin{tabular}{lccc}
\hline Complications & Immediate & Early & Late \\
\hline Surgical emphysema & 7 & 1 & 0 \\
$\quad$ Minor & 4 & 0 & 0 \\
$\quad$ Major & 12 & 8 & 0 \\
Tube malposition & 8 & 7 & 3 \\
Tube block & 2 & 0 & 3 \\
Accidental decannulation & 11 & 1 & 0 \\
Bleeding & 1 & 11 & 1 \\
Lung atelectasis & 0 & 7 & 3 \\
Stomal infection & 0 & 1 & 3 \\
Tracheitis & 0 & 2 & 20 \\
Stomal granulation & 0 & 0 & 18 \\
Tracheal granuloma & 0 & 0 & 27 \\
Pneumonia & 0 & 0 & 9 \\
Suprastomal collapse & 0 & 0 & 1 \\
Stomal stenosis & 0 & 0 & 2 \\
Tracheal stenosis & 0 & 0 & 3 \\
Tracheocutaneous fistula & 0 & 0 & 1 \\
Tracheomalacia & & & \\
\hline & & 0 & 3 \\
\hline
\end{tabular}

indication. ${ }^{19,20}$ With better airway management and improving critical care, more number of tracheostomies were performed for prolonged ventilation, cardiopulmonary diseases, and neurological impairment. ${ }^{21-25}$ Interestingly, we found that UAO obstruction was the most common indication from 2000 to 2009 and CNI was the most frequent indication for tracheostomy from 2010 to 2018. Possible reasons for this change are improved and aggressive in neurocritical care, better airway management, and early surgical interventions with better techniques for congenital airway obstructive lesions. Seventeen (13.5\%) patients were tracheostomized for acquired subglottic stenosis in the first 10 years as compared to seven (4.3\%) in later years ( $p$ value 0.005 ). This is probably related to the availability of better endotracheal tubes, use of sedation and analgesics in intubated children, improved nursing care, and attempts to extubate early.

It seems that the average age at the time of tracheostomy in different studies depended on the most frequent indication. ${ }^{25}$ Younger age-group was reported in studies in which UAO, craniofacial anomalies, and cardiac diseases were predominant indications ${ }^{4,18}$ while older age $>3$ years was observed in studies when neurological impairment was the cause in the majority of children. ${ }^{23,24} \mathrm{~A}$ similar observation was present in our study and by Lin et al. ${ }^{24}$

The primary diagnosis of patients and indications for tracheostomy are often different and we have reported the same 
Table 5: Analysis of predictors of decannulation

\begin{tabular}{|c|c|c|c|c|c|}
\hline \multirow[b]{2}{*}{ Variables } & \multicolumn{3}{|c|}{ Univariate analysis } & \multicolumn{2}{|c|}{ Multivariate analysis } \\
\hline & $\begin{array}{l}\text { No decannulation } \\
(n=102)\end{array}$ & $\begin{array}{l}\text { Decannulation } \\
(n=188)\end{array}$ & $p$ value & $\begin{array}{l}\text { Odds ratio } \\
(95 \% \mathrm{Cl})\end{array}$ & $p$ value \\
\hline Age $<1$ year & $42(41.2)^{a}$ & $55(29.3)$ & 0.04 & $0.378(0.187-0.764)$ & 0.007 \\
\hline \multicolumn{6}{|l|}{ Indications } \\
\hline UAO & $19(18.6)$ & $67(35.6)$ & 0.004 & $2.647(1.182-5.924)$ & 0.018 \\
\hline $\mathrm{CNI}$ & $48(47)$ & $74(39.3)$ & 0.17 & & \\
\hline PV & $22(21.5)$ & $29(15.4)$ & 0.19 & & \\
\hline NMD & $10(9.8)$ & $21(11.1)$ & 0.73 & & \\
\hline \multicolumn{6}{|l|}{ Diagnosis } \\
\hline Trauma & $8(7.8)$ & $37(19.7)$ & 0.007 & & \\
\hline CP disease & $13(12.7)$ & $9(4.8)$ & 0.01 & & \\
\hline CNS disease & $20(19.6)$ & $19(10)$ & 0.01 & $0.398(0.186-0.855)$ & 0.018 \\
\hline Malignancy & $13(12.7)$ & $3(1.6)$ & 0.0001 & $0.078(0.021-0.298)$ & $<0.001$ \\
\hline \multicolumn{6}{|l|}{ Days on MV } \\
\hline Pretrach & $12.5(8.7,20.2)^{b}$ & $11(4,17.7)$ & 0.02 & & \\
\hline Posttrach & $10(4,22)$ & $5(2,12)$ & $<0.0001$ & $0.937(0.893-0.983)$ & 0.008 \\
\hline \multicolumn{6}{|c|}{ Length of stay (days) } \\
\hline \multicolumn{6}{|c|}{ PICU } \\
\hline Pretrach & $13.4(9,22)$ & $11.8(4.6,18.2)$ & 0.02 & & \\
\hline Posttrach & $13.5(8,28)$ & $10(7,20)$ & 0.02 & 0.989 (0.979-0.999) & 0.029 \\
\hline Total & $31(19,50)$ & $24(13,40)$ & 0.002 & & \\
\hline \multicolumn{6}{|l|}{ Hospital } \\
\hline Posttrach & $19.5(12,34.5)$ & $22(13,40)$ & 0.48 & & \\
\hline Total & $36.5(24.7,61.2)$ & $37(21,56.5)$ & 0.32 & & \\
\hline \multicolumn{6}{|l|}{ Outcome } \\
\hline Trach (days) & $67(25.7,216.2)$ & $157(85.5,317.5)$ & $<0.001$ & & \\
\hline Survivor & $13(12.7)$ & $186(98.9)$ & $<0.0001$ & & \\
\hline
\end{tabular}

${ }^{a}$ Represents frequency and percentage in parentheses; ${ }^{b}$ Median with interquartile range; UAO, upper airway obstruction; CNI, central neurological impairment; PV, prolonged ventilation; NMD, neuromuscular disorders; $\mathrm{CP}$, cardiopulmonary; CNS, central nervous system diseases due to nontraumatic noninfective causes; MV, mechanical ventilation; trach, tracheostomy

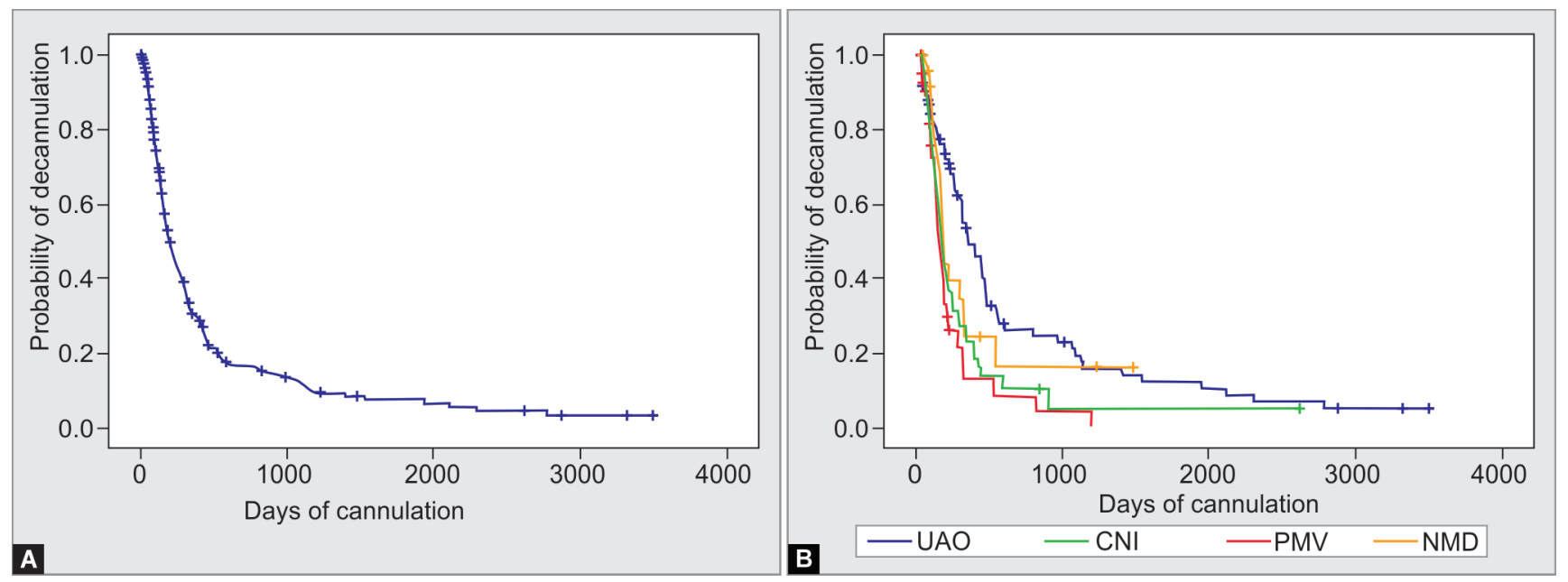

Figs 1A and B: Kaplan-Meier curves. Probability of decannulation with estimated mean \pm standard error (SE) and $95 \%$ Cl for whole study cohort (495.4 \pm 61.9 ; 374-616.7) and for different indications. UAO upper airway obstruction (704.3 \pm 110.5 ; 487.7-920.9), CNI central neurological impairment (374.8 \pm 93.8 ; 163.9-531.7), PMV prolonged mechanical ventilation (236.9 $\pm 51.3 ; 136.3-337.6)$, NMD neuromuscular disorders (412.6 $\pm 112.2 ; 192.6-632.6)$

way. Both have an association with the final outcome. McPherson et al. reported that the presence of an oncology process was associated with poor survival and unsuccessful decannulation. ${ }^{10}$ In the present study, diagnosis of cardiopulmonary diseases, nontraumatic noninfective central neurological diseases, and neoplasm/malignancy were associated with poor outcomes.

The overall complication rate was $61 \%$ in our series. There were 45 immediate, 38 early, and 94 late complications. Thirty- 
Table 6: Analysis of predictors of mortality

\begin{tabular}{|c|c|c|c|c|c|}
\hline \multirow[b]{2}{*}{ Variables } & \multicolumn{3}{|c|}{ Univariate analysis } & \multicolumn{2}{|c|}{ Multivariate analysis } \\
\hline & Survivor $(n=199)$ & Nonsurvivor $(n=91)$ & $p$ value & OR $(95 \% \mathrm{Cl})$ & $p$ value \\
\hline Age $<1$ year & $59(29.6)^{a}$ & $38(41.8)$ & 0.04 & $2.39(1.13-5.05)$ & 0.02 \\
\hline \multicolumn{6}{|l|}{ Indication } \\
\hline UAO & $71(35.6)$ & $15(16.4)$ & 0.0009 & $0.24(0.09-0.57)$ & $<0.001$ \\
\hline $\mathrm{CNI}$ & $76(38.2)$ & $46(50.5)$ & 0.05 & & \\
\hline PMV & $29(14.6)$ & $22(24.1)$ & 0.05 & & \\
\hline NMD & $23(11.5)$ & $8(8.8)$ & 0.49 & & \\
\hline \multicolumn{6}{|l|}{ Diagnosis } \\
\hline Airway disease & $31(15.6)$ & $5(5.5)$ & 0.015 & & \\
\hline Trauma & 39 (19.6) & $6(6.6)$ & 0.004 & & \\
\hline CP disease & $9(4.5)$ & $13(14.3)$ & 0.003 & & \\
\hline Malignancy & $3(1.5)$ & $13(14.3)$ & $<0.0001$ & $17.55(4.10-75.11)$ & $<0.001$ \\
\hline \multicolumn{6}{|l|}{ Days on MV } \\
\hline Pretrach & $10(3,17)^{b}$ & $14(9,21)$ & 0.001 & & \\
\hline Posttrach & $5(2,12)$ & $12(5,26)$ & $<0.001$ & $1.06(1.006-1.10)$ & 0.028 \\
\hline \multicolumn{6}{|l|}{ LOS (days) } \\
\hline \multicolumn{6}{|l|}{ PICU } \\
\hline Pretrach & $12.2(5.1,19.2)$ & $14.3(8.8,23)$ & 0.022 & & \\
\hline Posttrach & $10(7,20)$ & $14(9,23)$ & 0.002 & & \\
\hline Total & $24(12,40)$ & $33(20,51)$ & $<0.001$ & & \\
\hline \multicolumn{6}{|l|}{ Hospital } \\
\hline Posttrach & $22(13,34)$ & $21(13,35)$ & 0.71 & & \\
\hline Total & $36(21,55)$ & $42(26,62)$ & 0.035 & $1.007(1.0-1.013)$ & 0.043 \\
\hline
\end{tabular}

${ }^{a}$ Represents frequency and percentage in parentheses; ${ }^{b}$ Median with interquartile range; UAO, upper airway obstruction; CNI, central neurological impairment; PV, prolonged ventilation; NMD, neuromuscular disorders; $\mathrm{CP}$, cardiopulmonary; MV, mechanical ventilation; trach, tracheostomy; LOS, length of stay
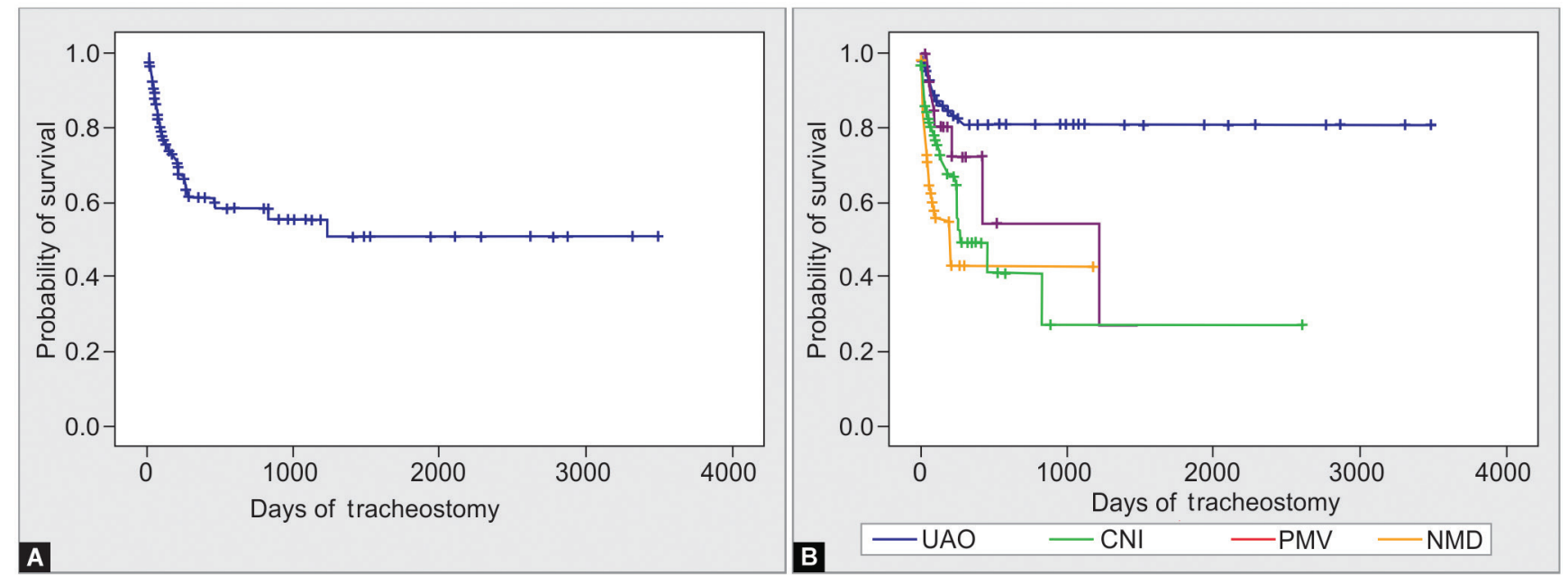

Figs 2A and B: Kaplan-Meier curves. Survival probability with estimate mean \pm SE and 95\% Cl for overall cohort (1903.6 $\pm 170 ; 1570.3-2236.9)$ and for different indications. UAO upper airway obstruction $(2803.3 \pm 162.5 ; 2484.6-3121.7)$, CNI central neurological impairment (888.8 \pm 245.1 ; 408.4-1369.2), PMV prolonged mechanical ventilation (551.5 $\pm 99.5 ; 356.3-746.6)$, NMD neuromuscular disorders (841 $\pm 184 ; 480.3-1201.7)$. UAO vs CNI $p$ value $<0.0001$, UAO vs PMV $p$ value $<0.0001$, PMD vs NMD $p$ value 0.02

two children had multiple complications at different time periods. The complication rate is higher and varies in different studies on pediatric tracheostomies (18-80\%) as compared to that in adults. ${ }^{5,18-21}$ The most dreaded immediate or early complications before the first tube change were tube block, accidental tube removal, and major surgical emphysema. There were five deaths before the first tube change in the present study. The incidence of posttracheostomy subcutaneous emphysema is between 10 and $17 \%$ in children. ${ }^{26}$ Perez et al. reported acute life-threatening tracheostomy occlusion and accidental decannulation in 29.3 and $15.2 \%$, respectively, and infection as late complications. ${ }^{27}$

Stomal and tracheal granulations constituted $40.4 \%$ of late complications in our study. Tracheal granuloma was diagnosed bronchoscopically. Not all suprastomal granulomas required 
intervention but were a concern at the time of decannulation. The incidence of granulomata varies from 12.5 to $56 \%$ in different studies. $^{4,5,16}$

Overall decannulation rate was $64.8 \%$ in our study and none of our patients required recannulation. The reported decannulation rate in children varied from 23 to $70 \% .^{2,4,18,27}$ Similar to our study, Zank et al. reported a higher rate of successful decannulation in UAO and trauma cases. ${ }^{22}$ On the contrary, Canning et al. reported UAO as high risk for unsuccessful decannulation. ${ }^{28}$ Other predictors for unsuccessful decannulation include age at the time of tracheostomy, neurological diseases particularly congenital disorders, anatomic airway diseases, failure to thrive, and cardiopulmonary diseases. ${ }^{10,18,29}$ Such wide variation in decannulation rate is related to patient population characteristics, differences in the categorization of indications, and variable follow-up periods.

In the present study, disease-related mortality was $28.3 \%$ and tracheostomy-related mortality was 3.1\%. Previous studies have reported wide variation in overall mortality from 2.9 to $59 \%$ and tracheostomy-related mortality from 0 to $4.2 \%$. ${ }^{6,9,30,31}$ A significant decrease in morbidity and mortality over decades has been reported in an extensive review of the literature. ${ }^{32} \mathrm{We}$ did not observe a similar change over two decades. In our study, more children with cardiopulmonary diseases, nontraumatic noninfective central nervous system diseases, and malignancy died with tracheostomy in situ. A similar observation was reported in previous studies. ${ }^{10,16}$

Our study has some limitations and strengths. This is a single-center study so results may not be applicable to other PICU population outcomes, especially in developed countries. A significant limitation relates to the lack of causes of death, particularly in those who died at home. We have not studied the details of readmission after tracheostomy, the number of failures before successful decannulation, quality of life, nutritional status of cases, resource utilization at the hospital, and burden on parents and family while taking care of a tracheostomized child. These are very important aspects that need more studies in the future. Extensive support is also required at home, playschool, and school to optimize a child's developmental outcome. Unfortunately, in resource-limited countries, it is impossible to provide home visits by trained nurses and social workers. So, children have to visit our hospital or some other health facilities for even minor problems and are totally dependent on parents and caregivers. The major strength of our study is the prospectively collected data with a large number of cases admitted in the PICU over two decades. Every effort was made to follow patients and communicate with parents through postal mail or telephonically and this was reflected in the outcome results.

\section{Conclusion}

Indications for tracheostomy in children had changed in resourcelimited countries. Decannulation and mortality were determined by the age of the patient at the time of tracheostomy, primary medical condition, and length of posttracheostomy ventilation and stay in the PICU and hospital. In the future, prospective studies are required on the timing of tracheostomy in children admitted to the PICU and its effects on morbidity and mortality and quality of life after discharge from the hospital.

\section{OrCID}

Anil Sachdev (1) https://orcid.org/0000-0002-7624-6985 Nilay D Chaudhari 이 https://orcid.org/0000-0002-9460-1274

Bhanu P Singh (1) https://orcid.org/0000-0002-5070-7683

Nikhil Sharma 은 https:/orcid.org/0000-0003-4198-2744

Dhiren Gupta @ https://orcid.org/0000-0002-8244-0768

Neeraj Gupta @i https://orcid.org/0000-0002-7131-4985

Suresh Gupta 으 https://orcid.org/0000-0002-5790-1366

Parul Chugh $\odot$ https://orcid.org/0000-0002-0582-0249

\section{References}

1. Carron JD, Derkay CS, Strope GL, Nosonchuk JE, Darrow DH. Pediatric tracheotomies: changing indications and outcomes. Laryngoscope 2000;110(7):1099-1104. DOI: 10.1097/00005537-200007000-00006.

2. Hadfield PJ, Lloyd-Faulconbridge RV, Almeyda J, Albert DM, Bailey CM. The changing indications for paediatric tracheostomy. Int Pediatr Otorhinolaryngol 2003;67(1):7-10. DOI: 10.1016/S0165-5876(02)00282-3.

3. Miswinter KI, Carrie S, Bull PD. Paediatric tracheostomy: Sheffield experience 1979-1999. J Laryngol Otol 2002;116(7):532-535. DOI: 10.1258/002221502760132403.

4. Mahadevan M, Barber C, Salkeld L, Douglas G, Mills N. Pediatric tracheotomy: 17 year review. Int J Pediatr Otorhinolaryngol 2007;71(12):1829-1835. DOI: 10.1016/j.ijporl.2007.08.007.

5. Carr MM, Puje CP, Kingston L, Kielma D, Heard C. Complications in pediatric tracheostomies. Laryngoscope 2001;11(11):1925-1928. DOI: 10.1097/00005537-200111000-00010.

6. Holscher CM, Stewart CL, Peltz ED, Burlew CC, Moulton SL, Haenel $\mathrm{JB}$, et al. Early tracheostomy improves outcomes in severely injured children and adolescents. J Pediatr Surg 2014;49(4):590-592. DOI: 10.1016/j.jpedsurg.2013.09.002.

7. Rane S, Bathula S, Thomas RL, Natarajan G. Outcomes of tracheostomy in the neonatal intensive care unit: is there an optimal time? J Matern Fetal Neonatal Med 2014;27(12):1257-1261. DOI: 10.3109/14767058.2013.860438.

8. Da Silva PSL, Waisberg J, Paulo CST, Colugnati F, Martins LC. Outcome of patients requiring tracheostomy in a pediatric intensive care unit. Pediatr Int 2005;47(5):554-559. DOI: 10.1111/j.1442-200x.2005.02118.x.

9. Graf JM, Montagnino BA, Hueckel R, McPherson ML. Pediatric tracheostomies: a recent experience from one academic center. Pediatr Crit Care Med 2008;9(1):96-100. DOI: 10.1097/01. PCC.0000298641.84257.53.

10. McPherson ML, Shekerdemian L, Goldsworthy M, Charles G. Minard CG, Nelson CS, et al. A decade of pediatric tracheostomies: Indications, outcomes, and long-term prognosis. Pediatr Pulmonol 2017;52(7):946-953. DOI: 10.1002/ppul.23657.

11. Ertugrul I, Kesici S, Bayrakci B, Unal OF. Tracheostomy in pediatric intensive care unit: when and where? Iran J Pediatr 2016;26(1):e2283. DOI: $10.5812 /$ ijp.2283.

12. Caprotta G, Tiszler M, Chávez X, Frydman J. Tracheostomy in pediatric critically ill patients. J Pediatr Intens Care 2012;1(4):201-205. DOI: 10.3233/PIC-12033.

13. Wood D, McShane P, Davis P. Tracheostomy in children admitted to paediatric intensive care. Arch Dis Child 2012;97(10):866-869. DOI: 10.1136/archdischild- 2011-301494.

14. Meyer-Macaulay CB, McNally JD, O’Hearn K, Katz SL, Thébaud B, Vaccani JP, et al. Factors impacting physician recommendation for tracheostomy placement in pediatric prolonged mechanical ventilation: a cross-sectional survey on stated practice. Pediatr Crit Care Med 2019;20(9):e423-e431. DOI: 10.1097/ PCC.0000000000002046.

15. Sachdev A, Ghimiri A, Gupta N, Gupta D. Pre-decannulation flexible bronchoscopy in tracheostomized children. Pediatr Surg Int 2017;33(11):1195-1200. DOI: 10.1007/s00383-017-4152-x. 
16. Al-Samri M, Mitchell I, Drummond DS, Bjornson C, Tracheostomy in children: a population-based experience over 17 years. Pediatr Pulmonol 2010;45(5):487-493. DOI: 10.1002/ppul.21206.

17. Schweiger C, Manica D, Becker CF, Abreu LSP, Manzini M, Sekine L, et al. Tracheostomy in children: a ten-year experience from a tertiary center in southern Brazil. Braz J Otorhinolaryngol 2017;83(6):627-632. DOI: 10.1016/j.bjorl.2016.08.002.

18. Chia AZH, Ng ZM, Pang YX, Ang AHC, Chow CCT, Teoh OH, et al. Epidemiology of pediatric tracheostomy and risk factors for poor outcomes: an 11-year single-center experience. Otolaryngol Head Neck Surg 2020;162(1):121-128. DOI: 10.1177/ 0194599819887096.

19. Adoga AA, Ma'an ND. Indications and outcome of pediatric tracheostomy: results from a Nigerian tertiary hospital. BMC Surg 2010;10:2. DOI: 10.1186/1471-2482-10-2. Available from: http://www. biomedcentral.com/1471-2482/10/2.

20. Sheth R, Chaudhari C, Damaniya V, Goyani B, Aiyer RG. Study of indications and complications of tracheostomy in pediatric age group. Int J Med Sci Public Health 2016;5(3):500-504. DOI: 10.5455/ ijmsph.2016.19102015132.

21. Ozmen S, Ozmen OA, Unal OF. Pediatric tracheotomies: a 37-year experience in 282 children, Int J Pediatr Otorhinolaryngol 2009;73(7):959-961. DOI: 10.1016/j.ijporl.2009.03.020.

22. Zenk J, Fyrmpas G, Zimmermann T, Koch M, Constantinidis J, Iro H. Tracheostomy in young patients: indications and long-term outcome. Eur Arch Otorhinolaryngol 2009;266(5):705-711. DOI: 10.1007/s00405008-0796-4.

23. Lele SJ, Stephen S, Raman EV. Changing indications for pediatric tracheotomy: An urban Indian study. Ind J Otolaryngol Head Neck Surg 2019;71(1):501-505. DOI: 10.1007/s12070-018-1373-1379.

24. Lin CY, Ting TT, Hsiao TY, Hsu WC. Pediatric tracheotomy: a comparison of outcomes and lengths of hospitalization between different indications. Int J Pediatr Otorhinolaryngol 2017;101:75-80. DOI: 10.1016/j.ijporl.2017.07.038.

25. Gergin O, Adil EA, Kawai K, Watters K, Moritz E, Rahbar R. Indications of pediatric tracheostomy over the last 30 years: has anything changed? Int J Pediatri Otorhinolaryngol 2016;87:144-147. DOI: 10.1016/j. ijporl.2016.06.018.

26. Pal N, Makhija N, Kiran U, Pal S. Posttracheostomy subcutaneous emphysema: a management plan. Paediatr Anaesth 2007;17(3):298 300. DOI: 10.1111/j.1460-9592.2006.02086.x.

27. Perez-Ruiz E, Aguilera PC, Perez-Frias J, Cols M, Barrio I, Torrent A, et al. Paediatric patients with a tracheostomy: a multicentre epidemiological study. Eur Respir J 2012;40(6):1502-1507. DOI: 10.1183/09031936.00164611.

28. Canning J, Mills N, Mahadevan M. Pediatric tracheostomy decannulation: when can decannulation be performed safely outside of the intensive care setting? A 10 year review from a single tertiary otolaryngology service. Int J Pediatr Otorhinolaryngo 2020;133:109986. DOI: 10.1016/j.ijporl.2020.109986.

29. Funamura JL, Durbin-Johnson B, Tollefson TT, Harrison J, Senders CW. Pediatric tracheotomy: indications and decannulation outcomes. Laryngoscope 2014;124(8):1952-1958. DOI: 10.1002/lary.24596.

30. Ilce Z, Celayir S, Tekand GT, Murat NS, Erdogan E, Yeker D. Tracheostomy in childhood: 20 years experience from a pediatric surgery clinic. Pediatr Int 2002;44(3):306-309. DOI: 10.1046/j.1442200X.2002.01554.x.

31. Rozsasi A, Kühnemann S. A single center 6 year experience with two types of pediatric tracheostomy. Int J Pediatr Otorhinolaryngol 2005;69(5):607-613. DOI: 10.1016/j.ijporl.2004.11.024.

32. Dal'Astra AP, Quirino AV, Caixêta JA, Avelino MA. Tracheostomy in childhood: review of the literature on complications and mortality over the last three decades. Braz J Otorhinolaryngol 2017;83(2:) 207-214. DOI: 10.1016/j.bjorl.2016.04.005. 